\title{
Acta
Biochimica
Polonica
}

Vol. 48 No. 2/2001

$579-584$

QUARTERLY

\section{Search for polyprenols in leaves of evergreen and deciduous Ericaceae plants ${ }^{*}$}

\author{
Rajiv Ranjan ${ }^{1}$, Andrzej Marczewski ${ }^{2}$, Tadeusz Chojnacki ${ }^{3}$, J ozefina Hertel ${ }^{3}$ and \\ E wa Swiezewska ${ }^{3 \Omega}$
}

${ }^{1}$ Department of B otany, T.P. Varma College, Bihar, India; ${ }^{2}$ Botanical Garden-Center for B iological Diversity Conservation, Polish A cademy of Sciences, W arszawa, Poland; ${ }^{3}$ In sti tuteof Biochemistry and B iophysics, Pol ish A cad emy of Sci ences, W arszawa, Po land

Received: 17 August, 2000; re vised: 24J an u ary, 2001; ac cepted: 2 March, 2001

Key words: polyprenols, chemotaxonomy, se nes cence, Ericaceae

\begin{abstract}
Var i ous spe cies and cultivars of Ericaceae fam ily were checked for the pres ence of long-chain polyprenols in their leaves. In the ge nus Rhododendron no polyprenols were found in the ever-green spe cies, while they were pres ent in the de cid u ous type. The polyprenols were of chain-length of 14-20 isoprene res i dues and they oc curred in the form of acetic acid esters. The polyprenol accumulation is dis cussed with respect to se nes cence of leaves.
\end{abstract}

The presence of long-chain polyprenols (Fig. 1) in leaves was doc u mented in the number of botanical systematic groups and was suggested to be a chemotaxonomic criterion (Swiezewska et al., 1994) -a spe cies (ge nus or even family - e.g. Pinaceae) specific feature, i.e. the same polyprenol pattern is observed independently of the geographical origin of the plant (Ibata et al., 1984; Swiezewska \& Chojnacki, 1988). This phe nom enon was confirmed for over 2000 plant speciesstud ied in our laboratory (Swiezewska et al., 1994).
It has been observed that the content of polyprenols in leaves in creases with the age of the leaf and that in some species the age-dependent accumulation of polyprenols may at tain ex tremely high val ues (W ellburn \& Hemming, 1966; Swiezewska et al., 1994). The search for polyprenols in the members of the family Ericaceae, reported in the present paper, is a part of our program of research aimed at finding the general rules governing the accumulation of polyprenols.

\footnotetext{
TheB.R.A.Bihar Uni ver sity, Muzaffarpur, In dia is acknowl edged for grant ing a study leavetoR. Ranjan. Thanks are due to the Sti pend F und at the In sti tute of Bio chem is try and Bio phys ics for the grant provided to Dr. R. Ranjan.

$\Omega_{\text {To whom cor respon denceshould bead dressed. }}$
} 
In our previ ous stud ies the fam ilyE ricaceae has never been studied thoroughly. There were single observations on the presence of long-chain polyprenols composed of 16-19 isoprene res i dues in leaves of Vaccinium vitis idaea (Swiezewska etal ., 1994) and on the lack

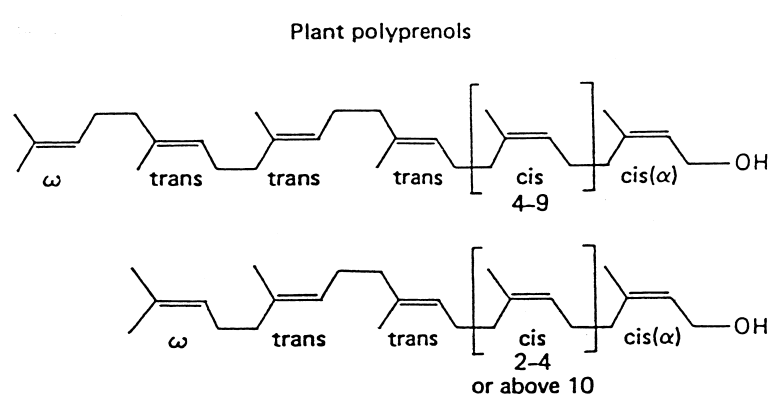

Fig ure 1. Struc ture of polyprenols

of polyprenols in leaves of some Rhododendron spe cies. Our aim to study plant spe cies of the E ricaceaefam ily in a sys tem atic way came from the observation that one R hododendron spe cies which oc curs in a wild state in Po land and was listed in the group of rare and en dangered Polish plants ( $\mathrm{Rh}$. luteum) was polyprenol pos i tive (Golas et al., 2001). The ge nus $\mathrm{R}$ hododendron was found to be attractive for our studies on the occurrence of polyprenols as it is a phylogenetically old group. Some of the species were present in their contemporary form even before 50 million years. The group of rhododendrons is very numer ousas it contains over 850 species. They occur mainly in the north ern hemi sphere. The va riety of species offers a great range of forms from tiny pros trate alpines to a tree with enormous leaves.

The present studies could have been made ow ing to the ac cess to the col lec tion of the Botan i cal Gar den of the Pol ish Acad emy of Sciences in Powsin. The rhododendrons present there have been col lected since 1978 and they include over 300 taxa. All together 440 taxa from the Heath fam ily (Marczewski, 1995) are cul ti vated. M ost of the col lected taxa were obtained from other bo tan i cal gar dens as seeds.
The great number of species within the genus $R$ hododendron enabled us to select the most characteristic morphological forms of plants, especially the largest group of evergreen plants with their sev eral va ri et ies, and a representative group of deciduous plant species.

In other group of the species studied belonging to Ericaceae, was confined to various azaleas and other species, some of which are also com mon in Po land. The to tal num ber of E ricaceae is es ti mated by var i ous authors to contain 130 genera and about 2700 species.

\section{MATERIALS AND METHODS}

The specimens of leaves of all studied species were col lected in the Ar bo re tum of the Bo tanical Garden of the Polish Academy of Sciences in Powsin near Warsaw. Samples of leaves were col lected in the first de cade of October 1999 and kept in paper envelopes for about 3 weeks before examination. During that time they became dry.

All chemicals, organic solvents of analytical grade(POCh Gliwice, Poland) and ma teri als for thin-layer chromatography (M erck, Darmstadt, Germany) were the same as previously described (Swiezewska \& Chojnacki, 1996).

Ex trac tion of lipids of leaves was done as de scribed previously (Swiezewska \& Chojnacki, 1996) with some modifications, namely 100 mg samples of plant material were homogenized in $4 \mathrm{ml}$ of acetone/ hexane, 1:1 (v/ v). TLC chromatography and semiquantitative assay of the polyprenol content was done as described before (Swiezewska \& Chojnacki, 1996; W ellburn \& Hemming, 1966). The standards of polyprenols and polyprenyl acetates were from the "Col lec tion of Polyprenols", Insti tute of Biochem istry and Biophysics, Polish Academy of Sciences, Warsaw.

Al ka linehy droly sis of lipid fraction was performed according to Stone et al. (1967) and 
the fraction of free polyprenols was isolated by chromatography of unsaponifiable lipids on Silica Gel col umn with in creas ing con centra tions of ethyl ether in hex ane. A $0.8 \times 6.0$ $\mathrm{cm}$ column was used to fractionate the unsaponifiable lipids from up to $5 \mathrm{~g}$ of dry leaves. The total volume of $150 \mathrm{ml}$ of the eluent $(7.5 \mathrm{ml}$ portions of hexane containing $1,2,3$ etc. up to $20 \%$ of ethyl ether) was used for elution. The fraction of free polyprenols was eluted with $8-10 \%$ ethyl ether.

The fraction of polyprenols was studied by HPLC on reversed phase RP-18 column in a solvent system as described previously (Swiezewska \& Chojnacki, 1996) using a Waters dual pump apparatus and a UV detector set at $210 \mathrm{~nm}$. Standard mixture of polyhprenols of var i ous chain length (prenologues composed of $9,10, \ldots$ etc. up to 25 isoprene units) was used to cal i brate the H PLC col umn between each 2-3 analyses. The polyprenol fraction was also ex am ined by ${ }^{1} \mathrm{H}-\mathrm{NMR}$ spectrometry in deuterochloroform in a Varian $500 \mathrm{MHz}$ apparatus using tetramethylsilane as internal standard.

\section{RESULTS AND DISCUSSION}

Thirty seven rhododendron species were stud ied for the con tent of polyprenols. No de tect able amounts of polyprenols or polyprenyl es ters were found in any of the fol low ing nine teen evergreen rhododendron species: $\mathrm{Rh}$. auriculatum Hemsl., Rh. brachycarpum D.Don, Rh. brachycarpum subsp. tigerstedti Nitz., Rh. campanulatum D.Don, Rh. carolinianum Rehder, Rh. catawbiense F.Michx., $R h$. dauricum L., Rh. degronianum subsp. heptam. (Maxim) Sealy, Rh. fastigiatum Franch., Rh. ferrugineum L., Rh. impeditum Balf.f. \& W.W.Sm., Rh. macrophyllum D.Don, Rh. maximum L., Rh. micranthum Turcz., Rh. oreodoxa Franch., Rh. orbiculare DC, Rh. oreotrephes W.W.Sm., Rh. purdomii Rehd. \& Wils., Rh. smirnowii Trautv., Rh. yakushimanum Nakai. The sensitivity of the applied semiquantitative assay enables us to state that if any amount of polyprenol or polyprenyl ester was present in the leaves, its amount was be low the limit of de tec tion i.e. less than $0.02 \%$ of the dry mass of leaves.

Thelist of names of var $i$ ous local va ri et ies of evergreen type rhododendrons that were found to be polyprenol negative is as follows: 'Alfred', 'America', 'Arno', 'Boursalt', 'Burgemeester Aarts', 'Caractacus', 'Cataw biense Boursault', 'Catharina van Tol', 'Cunningham's White', 'Dora Webbach', 'Dr H.C. Dresselhuys', 'Duke of York', 'Dyr. Frankowski', 'Edward S.Rand', 'Effner', 'Everstianum', 'Godman', 'Fastuosum Plenum', 'Lee's Dark Purple', 'Motyl', 'Parsons Gloriosum', 'Rose Marie', 'Silva Taruoca', 'Van der Hoop', 'Van W eerden Poelman'.

In Table 1 the results for fifteen rhododendrons of deciduous type (1-15) and three of semideciduous type (16-18) were shown. In this group of rhododendrons all 18 species were found to con tain de tect able though variable amounts of polyprenols (in the form of acetates) from $0.2 \%$ to $1.0 \%$ dry mass of leaves.

The iden tity of these sub stances was proved by cochromatography with known amounts of polyprenyl acetates isolated from leaves of Ginkgo biloba (Ibata et al., 1983).

Among 27 plant species of Ericaceae represent ing 16 gen era that were ex am ined for the presence of polyprenols only 5 have been found to be polyprenol positive and the content of polyprenols (in the form of acetates) was in the range be tween $0.2 \%$ and $1.0 \%$ of dry mass of leaves. The polyprenol content was not detectable in Andromeda glaucophylla Link, A. polifolia L., Arctostaphyllos uva-ursi (L.) Spreng., Bruckenthalia spiculifolia (Salisb.) Reichenb., Chamaedaphne calyculata (L.) Moench., Enkianthus campanulatus (M iq.) Nichols., Gaultheria cuneata (Rehder et Wilson) Bean, G. itoana Hyata, G. miqueliana Takeda, G. procubens L., G. shallon Pursh., Gaylussacia baccata (Wangenh.) K.Koch, Kalmia angustifolia L., K. latifolia L., Ledum palustre L., Leucothoe walteri (Willd.) M elvin, 
Ta ble 1.Polyprenols in leaves of rho do den drons of de cid u ous (1- 15) and semideciduous (16- 18) type

\begin{tabular}{ll}
\hline Name of species & $\begin{array}{l}\text { Con tent of } \\
\text { polyprenols } \\
\text { (\%dry mass) }\end{array}$ \\
\hline 1. Rh. albrechtii Maxim & $0.05-0.2$ \\
2. Rh. arborescens (Pursh) Torr & $0.05-0.2$ \\
3. Rh. atlanticum Rehder & $0.20-1.0$ \\
4. Rh. calendulaceum Torr & $0.20-1.0$ \\
5. Rh. camtschaticum Pall & $0.05-0.2$ \\
6. Rh. canadense Torr & $0.20-1.0$ \\
7. Rh. gandavense Rheder & $0.20-1.0$ \\
8. Rh. japonicum (Gray) Suring & $0.20-1.0$ \\
9. Rh. luteum Sweet & $0.05-0.2$ \\
10. Rh. prinophyllum (Small) Millais & $0.20-1.0$ \\
11. Rh. reticulatum D.Don & $0.05-0.2$ \\
12. Rh. schlippenbachii Maxim. & $0.05-0.2$ \\
13. Rh. semiobarbatum Maxim. & $0.05-0.2$ \\
14. Rh. vaseyi Gray & $0.20-1.0$ \\
15. Rh. viscosum Torr. & $0.20-1.0$ \\
16. Rh. kaempheri Planch. & $0.05-0.2$ \\
17. Rh. obtusum Planch. & $0.05-0.2$ \\
18. Rh. poukhanense Level. & $0.05-0.2$ \\
\hline
\end{tabular}

Lyonia ligustriana (L.) DC, Pieris floribunda (Pursh) Benth.et Hook.f., P.japonica (Thunb.) D.Don, P. polita W.W.Sm. et J .F.J effrey, P. taiwaniensis Hayata.

The size of the polyprenol molecules in the few polyprenol-positive non-rhododendron E ricaceae was sim i lar to that in the rho do dendrons of decid u ous type. In each species the polyprenol family was composed of several prenologues ranging from 14 to 20 isoprene residues. The typical representative polyprenol pattern of various plant species studied in this pa per is shown in Fig. 2. The dom inat ing polyprenol was built up from ei ther 17 , 18 or 19 isoprene units.

In Fig. 3 the ${ }^{1}$ H-N M R spec trum of polyprenol mixtures isolated from Rhododendron viscosum (listed in Ta ble 1; No.15) is shown. In the record the peaks of the char acter is tic protons of polyprenol mol eculearevisi ble. Theassignments of in di vid ual peaks are shown in theaccompanyinglegend. The majority of isoprene units are in cis configuration, which is the characteristic feature of the $\mathrm{OH}$-terminal isoprene residue. There seems to be no dolichol component (with the saturated $\mathrm{OH}$-terminal res i due) as ev i dent from the absence of the characteristic multiplet at 3.6 ppm. The exact proportion between the cisand trans-isoprene units in the molecule cannot easily be given as the spectra represent mixtures of molecules of various size. The same type of spectrum, presenting a typical isoprenoid pattern was also obtained for the mixture of polyprenols prepared from another plant Oxydendrum arboreum, (not shown).

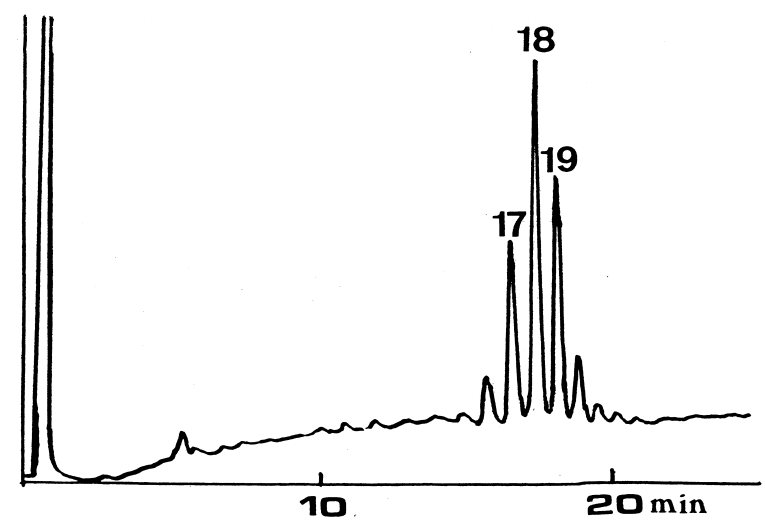

Fig ure 2. HPLC re cord of the polyprenols iso lated from Oxydendrum arboreum (L.) DC.

The numbers over the peaks mark the position of a given prenologue (17, prenol-17; 18, prenol-18; 19, prenol-19). For other details see Materials and Methods.

The „polyprenol pat tern" was char acter istic in all so far studied species of Magnoliaceae, M oraceae, etc. (Swiezewska et al., 1994). The main polyprenols in their leaves were prenol-10 and -11 . In sev eral other plant fam ilies we could observe the domination of prenol-19, -20 e.g. in Rosaceae. In the present pa per plants of fam ily E ricaceae have been examined for the presence of long chain polyprenols. The former trials have demon- 
strated that some Ericaceae contained polyprenols of the chain length of 16-19 isoprene units (e.g. Vaccinium vitis idaea) but in the evergreen rhododendrons the presence of polyprenols has never been detected. The deciduous type of rhododendrons as well as other members of Ericaceae were found to con tain polyprenols of sim i lar chain length (in the form of acetates).

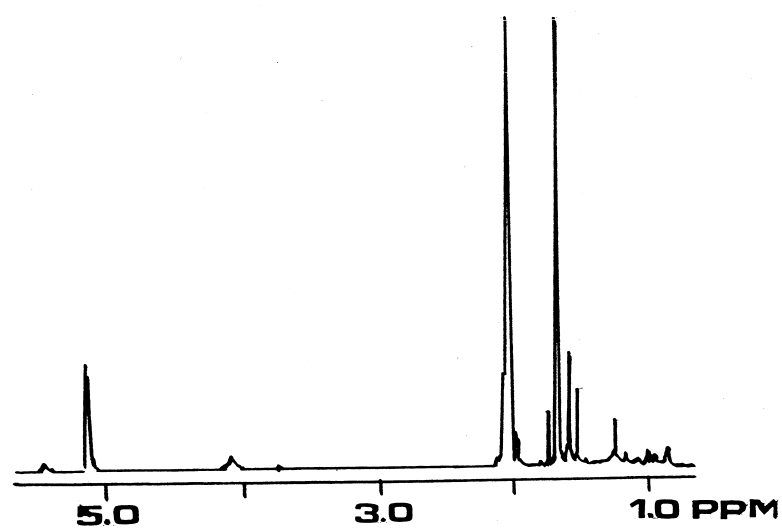

Fig ure $3 .{ }^{1}$ H-N M R spec trum of polyprenols of R hododen dron viscosum.

As sign ment of ${ }^{1} \mathrm{H}-\mathrm{NM} R$ sig nals

\begin{tabular}{ll} 
ppm & $\mathrm{Hy}$ drogen at oms (in ital ics) \\
\hline 1.60 & $-\mathrm{CH}_{3}$ trans, $-\mathrm{CH}_{3}$ trans (omega) \\
1.68 & $-\mathrm{CH}_{3}$ Cis, $-\mathrm{CH}_{3}$ Cis (omega) \\
1.74 & $-\mathrm{CH}_{3}$ Cis (al pha) \\
4.10 & $=\mathrm{CH}-\mathrm{CH}_{2}-\mathrm{OH}$ \\
5.12 & $=\mathrm{CH}-$ \\
5.45 & $=\mathrm{CH}-\mathrm{CH}_{2}-\mathrm{OH}$
\end{tabular}

The chro mato graphic and NMR spec tro metric characteristics of the polyprenols in polyprenols positive family of Ericaceae strongly indicate that they are of the same structure as those described for other plant families. It was though not possible to determine whether the polyprenols were of di-trans or tri-trans type. The highest amount of polyprenols reach ing the val ues of about $1 \%$ in studied plant species was of the same order ob served in sev eral plant spe cies (Swiezewska et al., 1994). The "polyprenol pat terns" of the studied Ericaceae were found to be similar to those of Pinaceae family (Ibata et al., 1984; Swiezewska \& Chojnacki, 1988) and of Ginkgo biloba (Ibata et al., 1983). The similarity of "polyprenol spec tra" in very dis tant groups of plants has been ob served ear lier in the case of species belonging to Cycadopisida and Rosaceae (Chojnacki et al., 1987). One can speculate that this similar ity may bethereflection of com mon function of these sub stances in the above mentioned distant groups of plants.

Since a long time it has been known that in deciduous plants de-greening of chloroplasts occurs during autumn and finally leads to death of leaves. A num ber of phys i ologi cal fac tors are in volved in this pro cess. In our de ciduous rhododendrons accumulation of poly prenols was observed dur ing au tumn. This is in agreement with theobserved accu mula tion

Table 2. Polyprenols in leaves of var $i$ ous Ericaeae

\begin{tabular}{ll}
\hline Name of species & $\begin{array}{l}\text { Con tent of } \\
\text { polyprenols } \\
\text { (\% dry mass) }\end{array}$ \\
\hline Lyonia mariana (L.) D.Don & $0.4-1.0$ \\
M enziesia pilosa (Michx.) J uss. & $0.2-1.0$ \\
Oxydendrum arboreum (L.) DC & $0.4-1.0$ \\
Vaccinium vitis idaea L. & $0.2-1.0$ \\
$\begin{array}{l}\text { Zenobia pulverulenta (W.Bartam } \\
\text { ex W ild.) Pol lard }\end{array}$ & $0.2-1.0$ \\
\hline
\end{tabular}

of polyprenols in de-greening leaves of var i ous representatives of R osaceae, Magnoliaceae and A nacardiaceae (not shown). The accumulation of polyprenols in the material studied may be due to the enhancement of a biosynthetic process, as it is the case of formation of secondary metabolites. The phenomenon of accumulation of polyprenols in some plants (and dolichols in aging animal cells (Chojnacki \& Dallner, 1988) deserves further investigation.

Our thanks should beex pressed to Pro fes sor St. Lewak of the University of Warsaw for 
helpful discussions and to Dr. J. Wójcik for NMR-analyses.

\section{R E F E R E N CE S}

Chojnacki, T. \& Dallner, G. (1988) The biological role of dolichol. Biochem. J. 251, 1-9.

Chojnacki, T., Swiezewska, E. \& Vogtman, T. (1987) Polyprenols from plants - structural analogues of mammalian dolichols. Chem. Scripta 27, 209- 214.

Ibata, K., Mizuno, M., Takigawa, T. \& Tanaka, Y. (1983) Long-chain betulaprenol-type polyprenols from the leaves of Ginkgo biloba. Biochem. J. 213, 305-311.

Ibata, K., Mizuno, M., Tanaka, Y.\& Kageyu, A. (1984) Long-chain polyprenols in the family Pinaceae. Phytochemistry 23, 783- 786.

Swiezewska, E. \& Chojnacki, T. (1988) Long-chain polyprenols in gymnosperm plants. Acta Biochim. Polon. 35, 131- 147.

Golas, U.A., Mozgawa, O.K., Gasek, A., Gawrys, W., Muranyi, R., Swiezewska, E.\& Chojnacki, T. (2001) Screening of Pol ish rare and en dangered plants for long-chain polyprenols. Biuletyn Ogrodow Botanicznych, Muzeów i Zbiorów (in press).
Marczewski, A. (1995) The arboretum of the Botanical Garden of the Polish Academy of Sciences in Powsin (in Pol ish with Eng lish summary). Biuletyn Ogrodów Botanicznych 4, 77-84.

Stone, K.J., Wellburn, A.R., Hemming, F.W. \& Morton, R.A. (1967) The characterization of ficaprenol-10, -11 and -12 from leaves of Ficus elastica (dec o rative rub ber plant). B iochem. J . 102, 313-324.

Swiezewska, E. \& Chojnacki, T. (1988) Long-chain polyprenols in gymnosperm plants. Acta Biochim. Polon. 35, 131- 147.

Swiezewska, E. \& Chojnacki, T. (1996) Polyprenols in leaves of fruit-trees of R osaceaefam ily. A cta Biochim. Polon. 43, 701- 702.

Swiezewska, E., Sasak, W., Mankowski, T., J ankowski, W., Vogtman, T., Krajewska, I., Hertel, J ., Skoczylas, E. \& Chojnacki, T. (1994) The search for plant polyprenols. Acta Biochim. Polon. 41, 211- 260.

Wellburn, A.R. \& Hemming, F.W. (1966) The occurrence and seasonal distribution of higher isoprenoid alcohols in the plant kingdom. Phytochemistry 5, 969- 975. 